\title{
The Properties of Thermosensitive Zwitterionic Sulfobetaine NIPAM-co-DMAAPS Polymer and the Hydrogels: The Effects of Monomer Concentration on the Transition Temperature and Its Correlation with the Adsorption Behavior
}

\author{
Eva Oktavia Ningrum ${ }^{1, *}$, Agus Purwanto ${ }^{2}$, Galuh Chynintya Rosita ${ }^{3}$, and Asep Bagus ${ }^{3}$ \\ ${ }^{1}$ Department of Industrial Chemical Engineering, Faculty of Vocational Studies, Institut Teknologi Sepuluh Nopember, \\ Kampus ITS Sukolilo, Surabaya, 60111, Indonesia \\ ${ }^{2}$ Department of Chemical Engineering, Faculty of Engineering, Universitas Sebelas Maret, \\ Jl. Ir. Sutami 36 A, Surakarta, Central Java 57126, Indonesia \\ ${ }^{3}$ Department of Chemical Engineering, Faculty of Industrial Technology, Institut Teknologi Sepuluh Nopember, \\ Kampus ITS Sukolilo, Surabaya 60111, Indonesia
}

* Corresponding author:

tel: $+62-81335233410$

email:eva-oktavia@chem-eng.its.ac.id

Received: December 1, 2018

Accepted: February 11, 2019

DOI: $10.22146 /$ ijc.41499

\begin{abstract}
The properties of $N$-isopropylacrylamide copolymerized with $N, N$-dimethyl (acrylamidopropyl)ammonium propane sulfonate [poly(NIPAM-co-DMAAPS)] prepared with various monomer ratios such as transition temperature, molecular structure, viscosity were systematically investigated in water and $\mathrm{Zn}\left(\mathrm{NO}_{3}\right)_{2}$ solution. Poly(NIPAMco-DMAAPS) in water and $\mathrm{Zn}\left(\mathrm{NO}_{3}\right)_{2}$ solution exhibited a phase transition with a lower critical solution temperature (LCST). The higher ratio of NIPAM monomer in poly(NIPAM-co-DMAAPS), the lower the LCST of the polymer. Furthermore, the transition temperature of poly(NIPAM-co-DMAAPS) with a lower NIPAM concentration were not confirmed both in water nor $\mathrm{Zn}\left(\mathrm{NO}_{3}\right)_{2}$ solution. The more increase the NIPAM concentration used in the preparation, the more increase the polymer viscosity. Moreover, the more increase the adsorption amount of ions onto the gel, the more increase the polymer transmittance as well.
\end{abstract}

Keywords: transition temperature; thermosensitive; adsorption

\section{- INTRODUCTION}

As the impact of highly industrial activities, the amount of heavy metals increases every year. Heavy metals can cause various adverse health effects because of their accumulation in the human body. It is not only dangerous for the human body but also the environment. Heavy metals are able to form a complex chain when it enters the organism body. One of the areas in Indonesia, which is affected by heavy metals is Jakarta Bay. The accumulation of heavy metals in Jakarta Bay has increased significantly from the 1970s. It is reported in 2017 that the heavy metal ions contamination which hits Jakarta Bay has spread far into Seribu Islands. Maintaining the sediment in the coastal area is the most vital action to be performed since it can affect the existence of various aquatic and benthic organisms. Additionally, it can provide them habitats and food supply. A phenomenon that becomes a serious environmental issue, and it should be immediately mitigated is the accumulation of heavy metals in the bottom sediment of Jakarta bay [1-2].

The issue of heavy metals separation becomes the concern of many parties. Conventional methods commonly used in the recovery of heavy metals from liquid industrial waste are activated sludge process, chemical precipitation, flotation, ion exchange, membrane filtration, and electrodialysis [3-6]. The most frequently studied for heavy metal wastewater treatment are ion-exchange, adsorption, and membrane filtration, and the most effective and an economical method for heavy metal wastewater treatment with low concentration is adsorption by low-cost adsorbents and biosorbents since it has a function as an alternative 
activated carbon (AC). Meanwhile, removing heavy metal ions with high efficiency can be done by using membrane filtration technology [7]. Activated sludge process is not effective because it results in sludge with high heavy metals concentration. The other methods are also not effective because of the high operation cost [8-10].

One of the novel technologies in heavy metals separation is by using adsorption with thermosensitive gel based on zwitterionic betaine as the adsorbent. This method is considered as the most effective to overcome the heavy metals contamination in the aquatic environment [11]. The advantage of zwitterionic betaine is having the ions selectivity as the consequence of the interaction among the ions and the positive and negative charges inside the chain [12]. Zwitterionic betaine is able to bond both anion and cation in liquid waste, simultaneously [13]. Zwitterionic betaine polymer is thermosensitive in aqueous solution, and also has Upper Critical Solution Temperature (UCST) or Lower Critical Solution Temperature (LCST) property or both of them. Besides, the zwitterionic gel is environmentally friendly and has a lower operational cost than the other methods.

Poly( $N$-isopropylacrylamide) [poly(NIPAM] is a thermosensitive polymer with Low Critical Solution Temperature (LCST) which is around $32{ }^{\circ} \mathrm{C}$. NIPAM swells at low temperature and shrinks at high temperature because of its transition from hydrophilic to hydrophobic and has neutral charge [14]. N,N'-dimethyl (acrylamidopropyl)ammonium propane sulfonate (DMAAPS) is zwitterionic sulfobetaine polymer. The previous study reports that physical condition and transparency of poly(DMAAPS) strongly affected by the concentration and the temperature of the solution. In high monomer concentration, poly(DMAAPS) physically forms gels because of the interchain in zwitterionic group. Poly(DMAAPS) solution points out the thermoresponsive phase transition at UCST. That polymer completely dissolves in $\mathrm{NaCl}$ solution at room temperature as same as in water at a temperature above the UCST [15]. Takahashi [14] has studied the thermosensitive polymer property of NIPAM-co-DMAAPS in a salt solution. The LCST of poly(NIPAM-co-DMAAPS) increases along with the increase of DMAAPS concentration and decreases along with the increase of the salt solution concentration. In our previous study [13], the correlation between the ions adsorption and swelling ability of sulfobetaine gel was investigated. The polymer concentration was considered to explain this relationship, which was converted from the density of the gel divided by its swelling degree. When the polymer concentration is higher than $180 \mathrm{~g} / \mathrm{L}$, the number of $\mathrm{Zn}^{2+}$ adsorbed onto the gel remains constant with the increase of polymer concentration.

In contrast, when the polymer concentration gets lower, the number of $\mathrm{Zn}^{2+}$ adsorbed increases with the increase of polymer concentration. The effects of crosslinker concentration on adsorption and the swelling ability of DMAAPS gel were also investigated in this study. The higher the cross-linker concentration, the better the adsorption ability of DMAAPS gel.

None of the preceding studies focus on the correlation between transition behavior of poly(NIPAM-co-DMAAPS) towards ions adsorption ability of NIPAM-co-DMAAPS gel. Most of which have emphasized phase transition and property of polymer in heavy metal solution or adsorption behavior of the gel independently. UCST poly(DMAAPS) depend strongly on molecular weight, sulfobetaine monomer, or polymer concentration and also environmental conditions $[13,16]$.

In the present study, the property of poly(NIPAMco-DMAAPS) such as molecular structure, viscosity, transition temperature was investigated with the variation of monomer concentration and using $\mathrm{Zn}\left(\mathrm{NO}_{3}\right)_{2}$ solution as target solution. The effects of monomer concentration on the transition temperature and its correlation with the adsorption behavior of the hydrogel were also elucidated.

\section{- EXPERIMENTAL SECTION}

\section{Materials}

The materials used in this research are $\mathrm{N}$ isopropylacrylamide (NIPAM, $\geq 99.52 \%$ ), 1,3-propane sultone, $\mathrm{N}, \mathrm{N}$-dimenthylaminopropylacrylamide (DMA PAA, $\geq 99.77 \%$ ), $N, N^{\prime}$-methylene-bisacrylamide (MBAA, 99\%), $N, N, N$, $N$ '-tetramethylethylenediamine (TEMED, 
99\%), ammonium peroxodisulfate (APS, $\geq 95 \%$ ), acetonitrile and acetone. The first material was bought from KJ Chemicals Co., Ltd., Japan. The second material was bought from Tokyo Chemical Industry Co., Ltd. The third material was supplied by KJ. Chemicals Co., Ltd., Japan. MBAA, TEMED, and APS were bought from Sigma Aldrich Co. (USA). Acetonitrile was bought from Avantor Performance Materials, while the last material which acetone was bought from Smart Lab Indonesia. Some materials were purified before being used, while some others were used as they were received. The materials that were used after being purified are NIPAM through recrystallization process and DMAPAA through vacuum distillation. Meanwhile, the other materials were used without purification.

\section{Synthesis of Poly[NIPAM-co-DMAAPS]}

A copolymer consisting of zwitterionic betaine $N, N$ dimethyl(acrylamidopropyl)ammonium propane sulfonate (DMAAPS) and thermosensitive $\mathrm{N}$ isopropylacrylamide (NIPAM) polymer and gel were characterized in order to elucidate the transition temperature and the adsorption amount of ions adsorbed onto the gel. The synthesis of NIPAM-co-DMAAPS is carried out in two steps; those are material purification and copolymer synthesis. The material purification step includes the purification of NIPAM and DMAPAA followed by the synthesis of DMAAPS monomer through a ring opening reaction of 1,3-propane sultone (PS) with $N, N^{\prime}$-dimethylaminopropylacrylamide (DMAPAA). NIPAM and DMAAPS monomers were then copolymerized to form poly(NIPAM-co-DMAAPS).

\section{Distillation of DMAPAA}

DMAPAA has a characteristic which is easily polymerized with each other. Thus the storage was added by hydroquinone as an inhibitor in order to prevent any polymerization reaction. Therefore, before its use, DMAPAA must be separated first from hydroquinone through vacuum distillation. The distillation was carried out at a vacuum pressure of $2 \mathrm{~cm}$ $\mathrm{Hg}$ and a temperature of $160^{\circ} \mathrm{C}$.

The product obtained was clear yellowish, while the residue of hydroquinone was darker brownish yellow. From the visualization of the resulting product color, it can be concluded that the purification/ separation process of DMAPAA from the impurities was successfully performed.

\section{Synthesis of DMAAPS}

The monomer of $\mathrm{N}, \mathrm{N}$-dimethyl(acrylamidopropyl) ammonium propane sulfonate (DMAAPS) was synthesized through ring opening reaction of $\mathrm{N}, \mathrm{N}$ dimethylaminopropylacrylamide (DMAPAA) and 1,3propane sultone (PS) proposed by Lee and Tsai [17] using the same method as in our previous study [18-20]. The following ring opening reaction occurs (Fig. 1).

DMAAPS is in the form of white crystal with a melting point of $105^{\circ} \mathrm{C}$ and a yield of $92 \%$. The formation of DMAAPS also involves the process of crystallization. The stirring is done to accelerate the formation of DMAAPS crystals. Acetone washing is done to remove the remaining acetonitrile and other impurities.

\section{Recrystallization of NIPAM}

The purification of NIPAM monomer is carried out by recrystallization from $n$-hexane. NIPAM (300 g) was dissolved in $510 \mathrm{~mL}$ benzene. The NIPAM-benzene solution was divided into six Erlenmeyer and added with hexane so that the total solution of NIPAM, benzene,

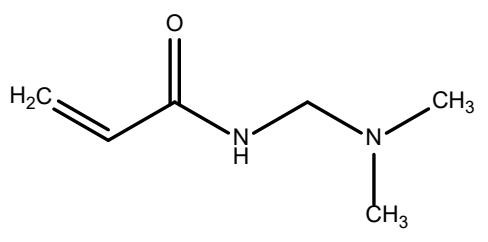

DMAPAA
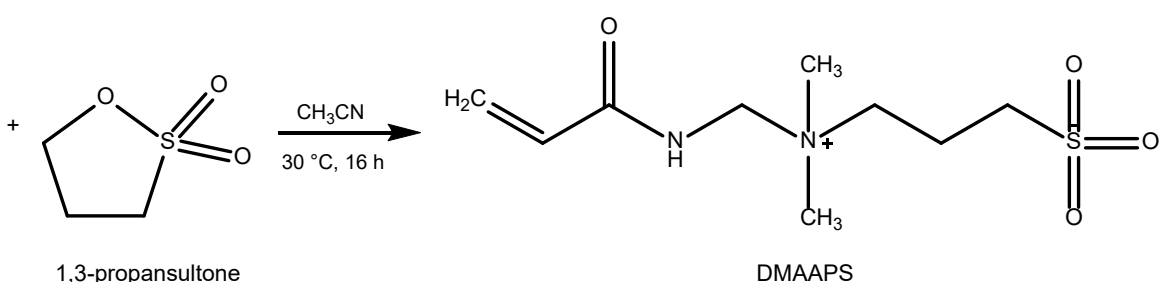

DMAAPS

Fig 1. Synthesis route to $N, N$-dimethyl(acrylamidopropyl)ammonium propane sulfonate (DMAAPS) through ring opening reaction 
and hexane was $1 \mathrm{~L}$. The solution was then put it in the refrigerator for a day. The product obtained was separated by a vacuum filter, followed by dried into a vacuum oven for $2 \mathrm{~h}$ at a constant temperature of $50^{\circ} \mathrm{C}$. Finally, NIPAM was ready to be used for the synthesis of the copolymer.

\section{Synthesis of copolymer}

Free radical polymerization was used to synthesize the poly(NIPAM-co-DMAAPS). The accelerator of the synthesis was TEMED, while the initiator was APS. In addition, the concentration of both accelerator and initiator used in preparing NIPAM-co-DMAAPS were 10 and $2 \mathrm{mmol} / \mathrm{L}$, respectively. NIPAM-co-DMAAPS were synthesized with NIPAM and DMAAPS molar ratio of 9:1, 8:2, and 7:3. The first solution was designated from NIPAM, which was dissolved in $50 \mathrm{~mL}$ of deionized water and put into a flask. The second solution was referred to as DMAAPS and TEMED, which were dissolved in aquadest of $50 \mathrm{~mL}$ put into another flask. The oxygen which was dissolved in the solution was then cleaned using nitrogen. A $20 \mathrm{~mL}$ of an aliquot from the APS of the dissolved purged oxygen was then added into a reactor containing the mixture of solution 1 and 2. The polymerization was conducted for $6 \mathrm{~h}$ at $10{ }^{\circ} \mathrm{C}$ under a nitrogen atmosphere. The reactions occur in the reactor were depicted in Fig. 2.

The release of radical persulfate ion from APS takes hydrogen atom from TEMED, so TEMED is activated and leaves molecule with a reactive unpaired electron was depicted in Fig. 3.

The activated TEMED attacks vinyl groups at NIPAM or DMAAPS to combine with it and activated in turn. As the chain of NIPAM or DMAAPS units grows, the active site shifts to the free end. The growing chain of NIPAM or DMAAPS joint together through their active site group.

\section{Synthesis of NIPAM-CO-DMAAPS gel}

NIPAM-co-DMAAPS gels were synthesized in the same way as copolymer synthesis. However, in this synthesis, the cross-linker was $30 \mathrm{mmol} / \mathrm{L}$ of MBAA. The DMAAPS with active site shown in Fig. 4 are then incorporated by NIPAM or MBAA, which consist of two acrylamides. They were joint together through $-\mathrm{CONH}_{2}$ groups lead to the formation of crosslinker between chains, as shown in Fig. 5.

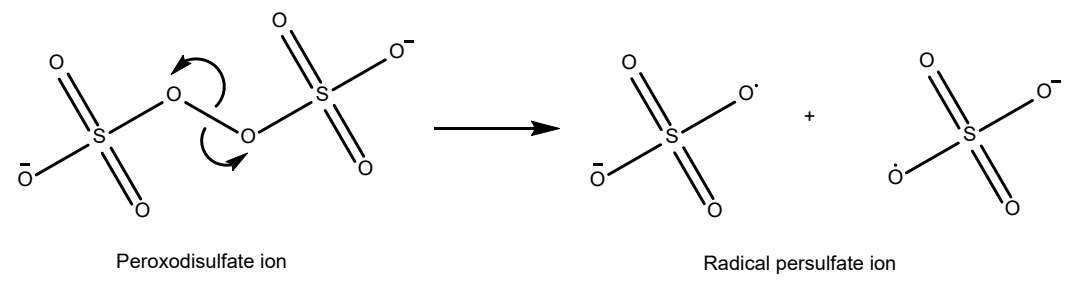

Fig 2. The release of radical persulfate ion from APS<smiles>CCCCCCN(C)CCN(C)CCN(C)CCN(C)C</smiles>

Fig 3. Activation of TEMED in the initiation stage of poly(NIPAM-co-DMAAPS) synthesis<smiles>C=CC(=O)NC[N+](C)(C)CCCS(=O)(=O)OC</smiles>

Fig 4. Propagation stage of DMAAPS chains 


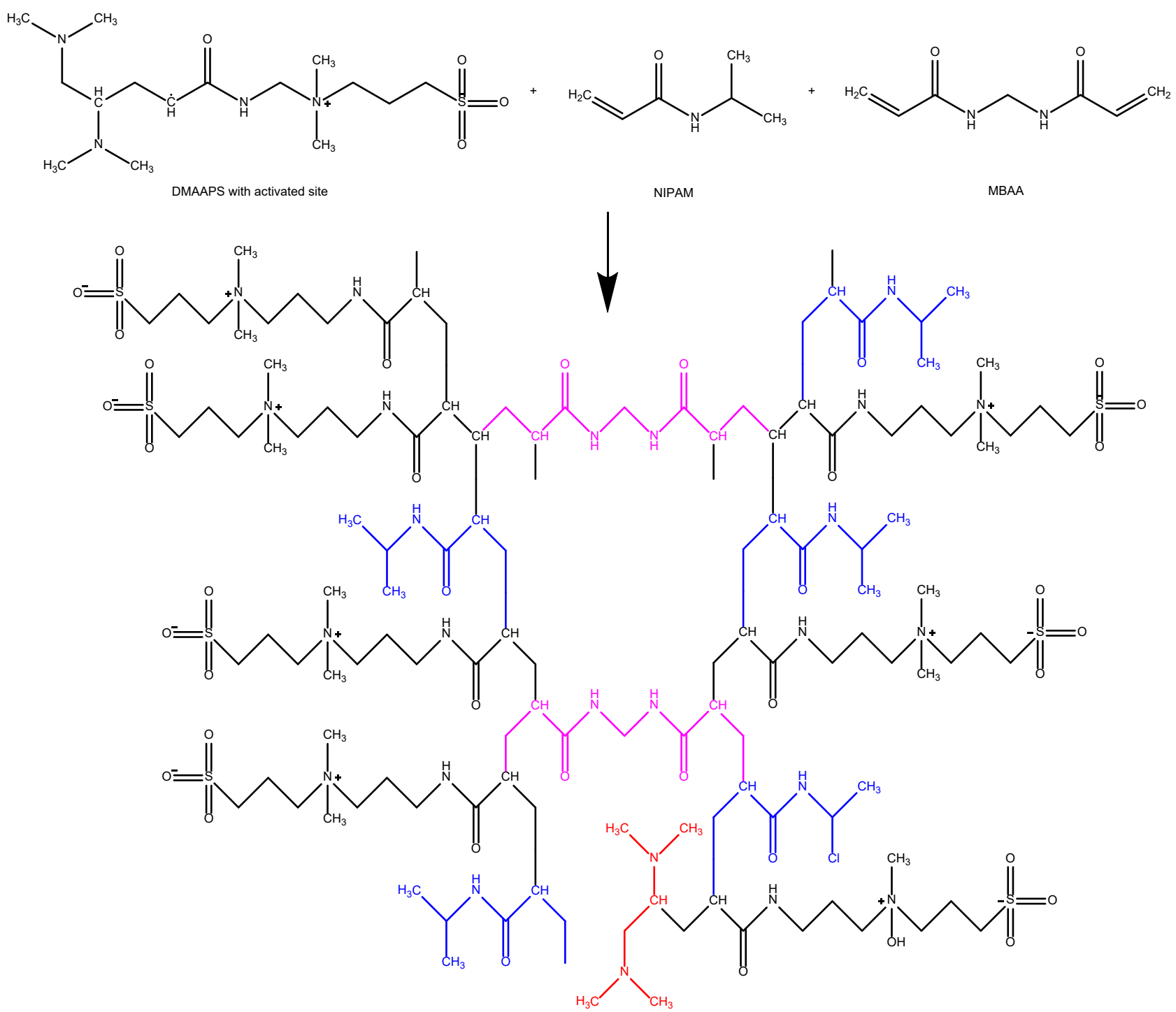

Fig 5. Chemical structure of $N, N$-dimethyl(acrylamidopropyl)ammonium propane sulfonate (DMAAPS), $N$ isopropylacrylamide (NIPAM), and NIPAM-co-DMAAPS gel (red: TEMED groups, black: DMAAPS groups, blue: NIPAM groups, magenta: MBAA groups)

Cylindrical tubes sized $30 \mathrm{~mm}$ in length, and $8 \mathrm{~mm}$ in diameter were placed inside the reactor for the preparation of the cylindrical gel. It was then cut into pieces of $8 \mathrm{~mm}$ in length and removed the unreacted monomers by being rinsed with distilled water. The gels were then dried on a Teflon sheet for 7 days. The Teflon sheet was spread on a Petri dish covered by a plastic film with small holes to make the drying goes slower since the gels tend to break apart if the drying is too fast. These cylindrical gels were used to measure the degree of swelling. The remaining gels were also cut into pieces, washed repeatedly for several days, dried in an oven, and grounded to make it into powder. The result was then filtered using a sieve with 90 mesh size. The final result would then be used for the adsorption experiments. The conditions employed in the synthesis of the NIPAM-coDMAAPS gels are shown in Table 1.

\section{Characterizations}

\section{Fourier Transform Infra-Red (FTIR) analysis}

Fourier Transform Infra-Red (FTIR, Thermo Fisher Scientific Nicolet IS10, USA) was used to identify 
Table 1. Synthesis condition of NIPAM-co-DMAAPS polymer and gel.

\begin{tabular}{lll}
\hline & & $\begin{array}{c}\text { Concentration } \\
(\mathrm{mmol} / \mathrm{L})\end{array}$ \\
\hline Monomer & $\mathrm{N}, N$-dimethyl(acrylamido-propyl)ammonium propane sulfonate (DMAAPS) & $100,200,300$ \\
& $N$-isopropylacrylamide (NIPAM) & $900,800,700$ \\
Cross-Linker & $N, N^{\prime}$-Methylenebisacrylamide (MBAA) & 10 \\
Accelerator & $N, N, N^{\prime}, N^{\prime}$-tetramethyl-ethylenediamine (TEMED) & 2 \\
Initiator & Ammonium peroxodisulfate (APS) & \\
\hline
\end{tabular}

Temperature: $10^{\circ} \mathrm{C}$, solvent: water, and reaction time: $6 \mathrm{~h}$

the synthesized structure. FTIR analysis was carried out to determine the presence of monomer and copolymer constituent functional groups. This analysis used middle area infra-red radiation in wavenumber of $4000-500 \mathrm{~cm}^{-1}$.

\section{Nuclear Magnetic Resonance (NMR) spectroscopy analysis}

NMR analysis was done to recognize the absolute structure of copolymer that has been synthesized. Agilent $500 \mathrm{MHz}$ NMR spectrometer was used to record the ${ }^{1} \mathrm{H}$ NMR spectra. It was conducted using DD2 console system. In this test, a copolymer with monomer ratio NIPAM:DMAAPS of 8:2 was used. The test was done by dissolving $20 \mathrm{mg}$ of the copolymer into $1 \mathrm{~mL}$ of $\mathrm{D}_{2} \mathrm{O}(20 \mathrm{~g} / \mathrm{L}$ $\mathrm{D}_{2} \mathrm{O}$ ) as the solvent.

\section{Transition temperature}

In order to investigate the transition temperature of poly(NIPAM-co-DMAAPS) in water and $\mathrm{Zn}\left(\mathrm{NO}_{3}\right)_{2}$ solution, the changes in the transmittance through the solutions with temperature were measured. An aqueous solution of poly(NIPAM-co-DMAAPS) becomes transparent, and the transmittance is almost $100 \%$ when it is at a temperature lower than the LCST since NIPAM has characteristics of hydrophilic and soluble in a solution. Meanwhile, if the solution is at a temperature above the LCST, it will become milky white, and the transmittance decreases since the poly(NIPAM-coDMAAPS) is hydrophobic and insoluble in the solution. In this case, a spectrophotometer completed by a temperature control system was used to measure the transmittance at $600 \mathrm{~nm}$. (JASCO Corp, V-630, Rev. $1.00)$. The concentration of poly(NIPAM-co-DMAAPS) in water and the heating rate were $1 \mathrm{wt} . \%$ and $1{ }^{\circ} \mathrm{C} / \mathrm{min}$, respectively.

\section{Viscosity}

In this stage, a Brookfield Digital Viscometer Model DV2T was used to obtain the viscosity of poly(NIPAM-co-DMAAPS) solution at various concentrations. The monomer ratio between NIPAM and DMAAPS were 9:1, 8:2, and 7:3 (10 g/L in water). In addition, the Brookfield Digital Viscometer used was also equipped by spindle No. 61 and 62, which have been found to be appropriately used for the viscosity measurement. The measurement was conducted at $27^{\circ} \mathrm{C}$, 10-20 rpm for 1-2 min. At least two readings mean were taken for each data point.

\section{Adsorption test}

In this study, the target solution used in the adsorption experiment was $\mathrm{Zn}\left(\mathrm{NO}_{3}\right)_{2}$. One gram of gel copolymer is added to the bottle glass containing $20 \mathrm{~mL}$ of an aqueous solution with a concentration of $10 \mathrm{mmol} / \mathrm{L}$. The glass bottle was then placed in a water bath followed by stirring for $12 \mathrm{~h}$ at the desired temperature to achieve equilibrium adsorption. In order to calculate the concentration of cations and anions in the solution after the adsorption process, the gel was separated from the solution by centrifuge for $10 \mathrm{~min}$. The gel was then filtered with a syringe filter. The following Eq. (1) was used to determine the amount of ions adsorbed onto the gel through the concentration of the ions. This measurement was done before and after the adsorption process.

$$
\mathrm{Q}=\frac{\left(\mathrm{C}_{0}-\mathrm{C}\right) \mathrm{V}}{\mathrm{m}}
$$

where $\mathrm{Q}$ is the number of cation $\left(\mathrm{Zn}^{2+}\right)$ or anion $\left(\mathrm{NO}_{3}^{-}\right)$ adsorbed, $\mathrm{C}_{0}$ is the concentration of ions in the solution before the adsorption process, $\mathrm{C}$ is the concentration of ions in the solution after the adsorption process, $\mathrm{V}$ is the 
solution volume, and $\mathrm{m}$ is the dry gel weight. Atomic Absorption Spectrophotometry analysis was conducted to measure the ions $\left(\mathrm{Zn}^{2+}\right.$ or $\left.\mathrm{NO}_{3}^{-}\right)$concentration (AAS, Model 210 VGP) analysis.

\section{- RESULTS AND DISCUSSION}

\section{The Analysis of Fourier Transform Infra-Red Spectroscopy (FTIR)}

FTIR analysis was conducted to determine the existence of functional groups composing NIPAM and DMAAPS monomers, as well as the NIPAM-co-DMAAPS copolymer. This analysis is used in the middle infrared radiation area from a wavelength of $4000-500 \mathrm{~cm}^{-1}$.

Fig. 6 shows the result of FTIR analysis of NIPAMco-DMAAPS copolymer with various monomer ratio NIPAM:DMAAPS of 9:1, 8:2 and 7:3 with a total concentration of $1000 \mathrm{mmol} / \mathrm{L}$. In the spectra comparison of the three copolymers above, it can be seen that the three copolymers have a very similar spectral pattern. The C-N bond can be seen around a wavenumber of $1170 \mathrm{~cm}^{-1}$. Meanwhile, $\mathrm{S}=\mathrm{O}$ bond is shown around $1387 \mathrm{~cm}^{-1}$ wavenumber. However, there is a slight difference in 9:1 copolymer spectra, which is a peak of $\mathrm{S}=\mathrm{O}$ and $\mathrm{C}-\mathrm{N}$ groups in the range of $1000-1500 \mathrm{~cm}^{-1}$ that is lower than in copolymer $8: 2$ and 7:3. This is because the number of
NIPAM is higher. Thus, the $\mathrm{S}=\mathrm{O}$ and $\mathrm{C}-\mathrm{N}$ groups from DMAAPS are less. In the three polymers, the N-H bond is shown at a wavenumber of $3280.17-3274.02 \mathrm{~cm}^{-1}$. A wavenumber reaching points 1629.1-1627.82 $\mathrm{cm}^{-1}$ indicates the presence of $\mathrm{C}=\mathrm{O}$ bond. The difference in the functional groups of each monomer and copolymer constituent is seen in the presence of vinyl groups of $\mathrm{CH}_{2}=\mathrm{CH}$ - which determines the success of the copolymer reaction. Vinyl bond $\left(\mathrm{CH}_{2}=\mathrm{CH}-\right)$ is located in the wavenumber range between 900 to $1000 \mathrm{~cm}^{-1}$. At NIPAM, vinyl bond $\left(\mathrm{CH}_{2}=\mathrm{CH}-\right)$ is seen at a wavenumber of $960.67 \mathrm{~cm}^{-1}$ (Fig. 6). At DMAAPS, the vinyl bond $\left(\mathrm{CH}_{2}=\mathrm{CH}-\right)$ is also seen at a wavenumber of $980.55 \mathrm{~cm}^{-1}$ (Fig. 6). However, on the result of FTIR analysis from NIPAM-co-DMAAPS (Fig. 6), there is no peak which shows $\mathrm{CH}_{2}=\mathrm{CH}$ - bond. This indicates the success of the copolymerization reaction between NIPAM and DMAAPS in forming the NIPAM-co-DMAAPS copolymer.

\section{The Analysis of Nuclear Magnetic Resonance (NMR) Spectroscopy}

The absolute structure of the poly(NIPAM-coDMAAPS) can be further determined by analyzing it using NMR spectroscopy. The ${ }^{1} \mathrm{H}$ NMR $(500 \mathrm{MHz})$

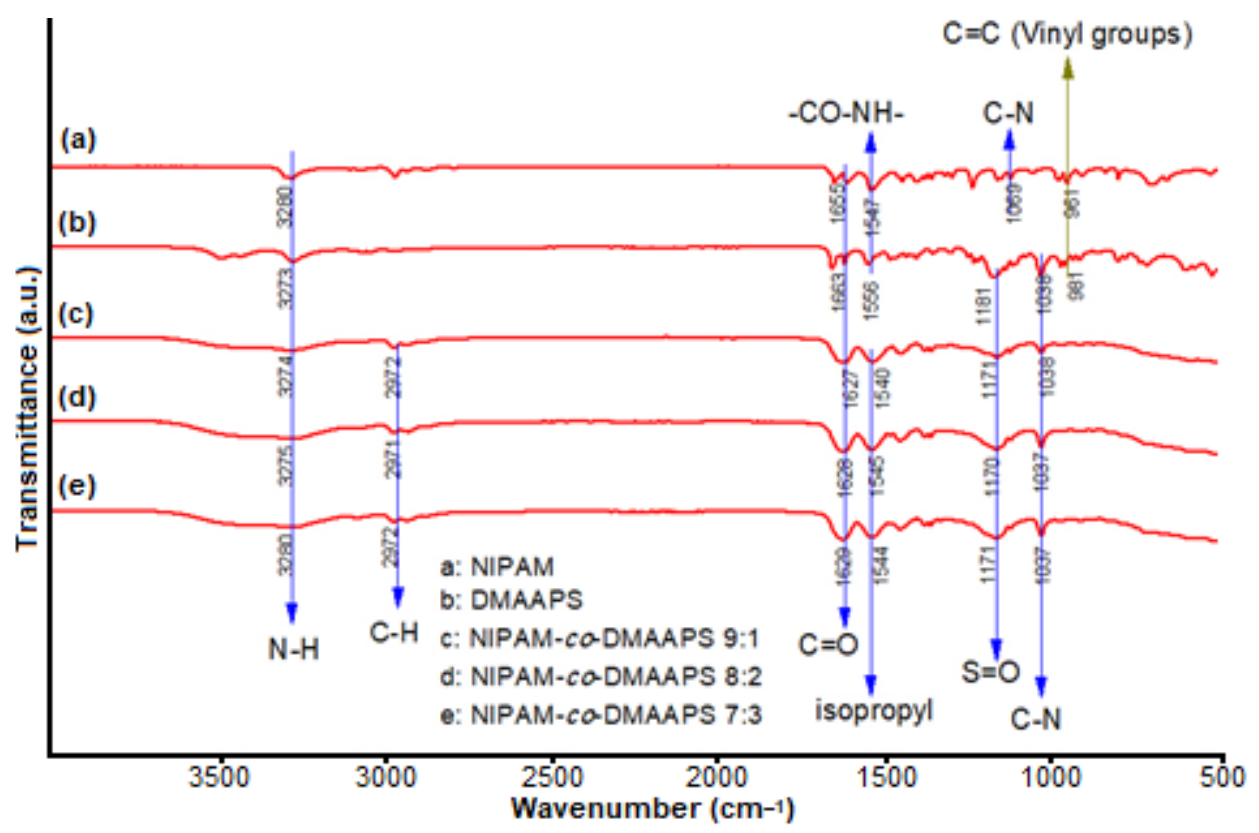

Fig 6. Infrared spectra of NIPAM, DMAAPS, and poly(NIPAM-co-DMAAPS) with various monomer ratios 
spectra of the copolymer with monomer ratio NIPAM:DMAAPS of 8:2 is shown in Fig. 7. The highest peak in range 4.6-4.7 was relative to the signal of the solvent. The results were as follows: ${ }^{1} \mathrm{H}$ NMR $[500 \mathrm{MHz}$, $\mathrm{D}_{2} \mathrm{O} \delta / \mathrm{ppm}$ ): 0.91-1.13 (s, 6H, $\left.\left(\mathrm{CH}_{3}-\mathrm{C}-\right)\right), 1.25-1.68$ (m, $\left.3 \mathrm{H},\left(-\mathrm{CH}_{2}-\mathrm{CH}-\right)\right), 1.8-2.05\left(\mathrm{~m}, 2 \mathrm{H},\left(-\mathrm{CH}_{2}-\mathrm{CH}_{2}-\mathrm{CH}_{2}-\right)\right.$ ), 2.1-2.2 (t, $\left.2 \mathrm{H},\left(-\mathrm{CH}_{2}-\mathrm{CH}_{2}-\mathrm{CH}_{2}-\right)\right), 2.5-2.7$ (t, $2 \mathrm{H},\left(-\mathrm{CH}_{2}-\right.$ $\left.\left.\mathrm{CH}_{2}-\mathrm{SO}^{3-}\right)\right), 2.92-3.08\left(\mathrm{~s}, 6 \mathrm{H},\left(\mathrm{CH}_{3}-\mathrm{N}^{+}-\mathrm{CH}_{3}\right)\right), 3.22-3.3(\mathrm{t}$, $\left.2 \mathrm{H},\left(-\mathrm{CH}_{2}-\mathrm{CH}_{2}-\mathrm{N}^{+}-\right)\right), 3.34-3.46\left(\mathrm{t}, 2 \mathrm{H},\left(-\mathrm{N}^{+}-\mathrm{CH}_{2}-\mathrm{CH}_{2}-\right)\right)$, 3.5-3.56 (t, $\left.\left.2 \mathrm{H},\left(-\mathrm{NH}-\mathrm{CH}_{2}-\mathrm{CH}_{2}-\right)\right), 3.7-3.86(\mathrm{~s}, 1 \mathrm{H}, \mathrm{CH})\right)$.

It is shown in Fig. 7 that a signal shown by a signal with code (a) and $(j)$ is a resonance signal for proton that constructs a NIPAM, i.e. $\mathrm{CH}_{3}$ and $\mathrm{CH}-\mathrm{N}$, while a signal shown by code (b), (c), (d), (e), (f), (g), and (h) was the proton signal that constructs DMAAPS i.e. $\mathrm{CH}_{2}-\mathrm{CH}$, $\mathrm{CH}_{2}-\mathrm{CH}_{2}-\mathrm{CH}_{2}, \mathrm{CH}_{2}-\mathrm{CH}_{2}-\mathrm{SO}^{3-}, \mathrm{CH}_{3}-\mathrm{N}^{+}-\mathrm{CH}_{3}, \mathrm{CH}_{2}-\mathrm{CH}_{2}-$ $\mathrm{N}$, and $\mathrm{NH}-\mathrm{CH}_{2}$, which are constituent monomers of poly(NIPAM-co-DMAAPS). All the chemical shifts in Fig. 7 are in good agreement with the literature, which shows that NIPAM-co-DMAAPS is indeed the target copolymer [21].

\section{Viscosity}

Both the characteristic of the copolymer in solution and the association of the polymer charged group are affected by viscosity. The high value of viscosity owned by substances affects the substance to have a low mass transfer rate since the copolymer viscosity affects the density of the gel formed. The higher the viscosity of the copolymer, the denser the gel. The viscosity of poly(NIPAM-co-DMAAPS) with various monomer ratios and with a polymer concentration of 10 g/L was measured at $27^{\circ} \mathrm{C}$. The result is shown in Fig. 8 for comparison purpose, the viscosity of the polymer was measured at various speeds, i.e., 10 and $20 \mathrm{rpm}$ and various time interval, i.e., 1 and $2 \mathrm{~min}$. The results show that the viscosity of poly(NIPAM-co-DMAAPS) with various monomer ratios NIPAM:DMAAPS of 9:1, 8:2, and 7:3 tend to increase with the increase of NIPAM concentration and was observed in the range of 20$120 \mathrm{cP}$. However, it was also observed that no significant change in viscosity according to each monomer ratio being indicated at various speeds and time intervals.

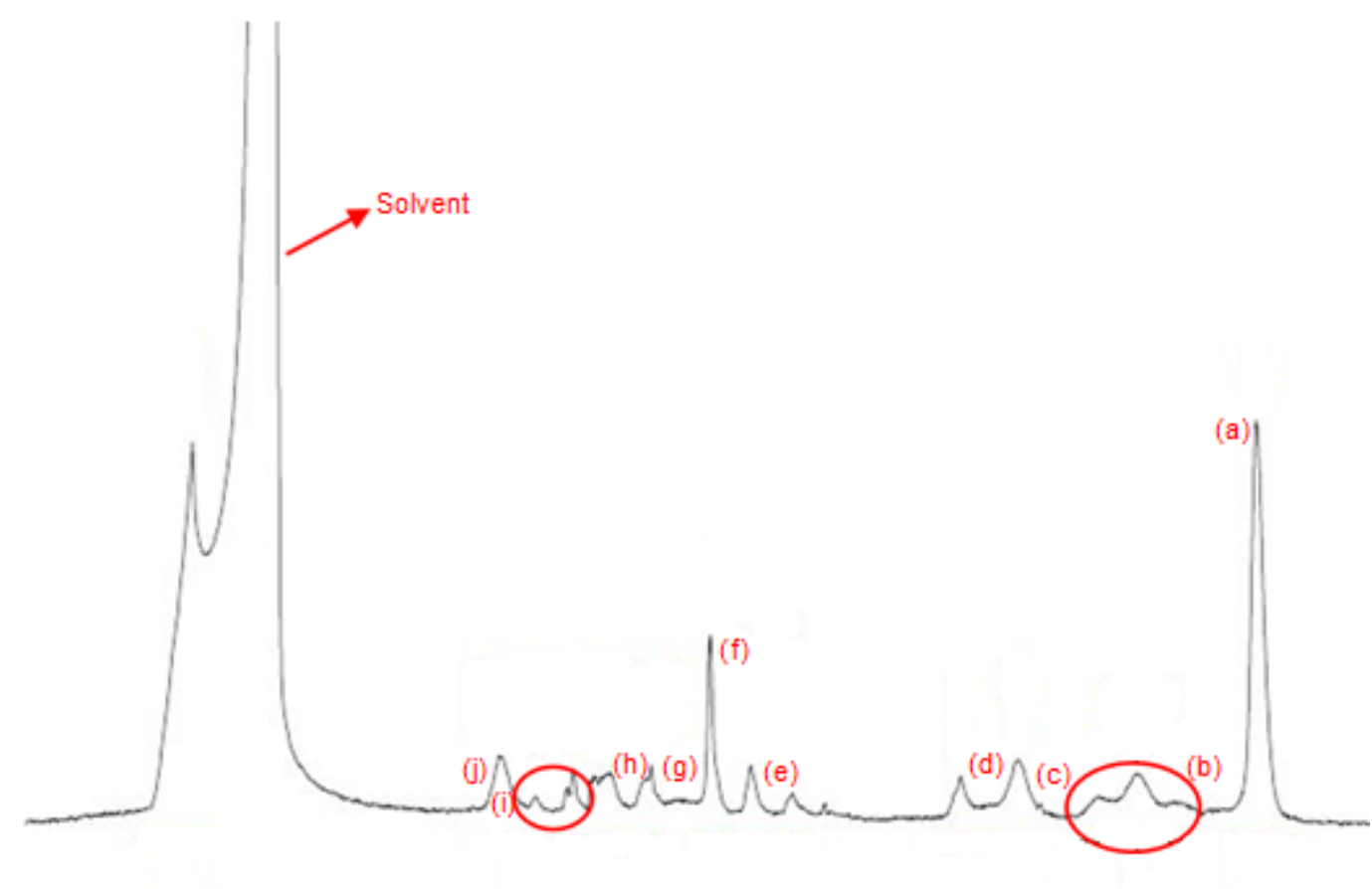

$\begin{array}{llllllllllllllllllllllllll}5.4 & 5.2 & 5.0 & 4.8 & 4.6 & 4.4 & 4.2 & 4.0 & 3.8 & 3.6 & 3.4 & 3.2 & 3.0 & 2.8 & 2.6 & 2.4 & 2.2 & 2.0 & 1.8 & 1.6 & 1.4 & 1.2 & 1.0 & 0.8\end{array}$

Fig 7. ${ }^{1} \mathrm{H}$ NMR spectrum of the poly(NIPAM-co-DMAAPS) with monomer ratio NIPAM:DMAAPS of 8:2 


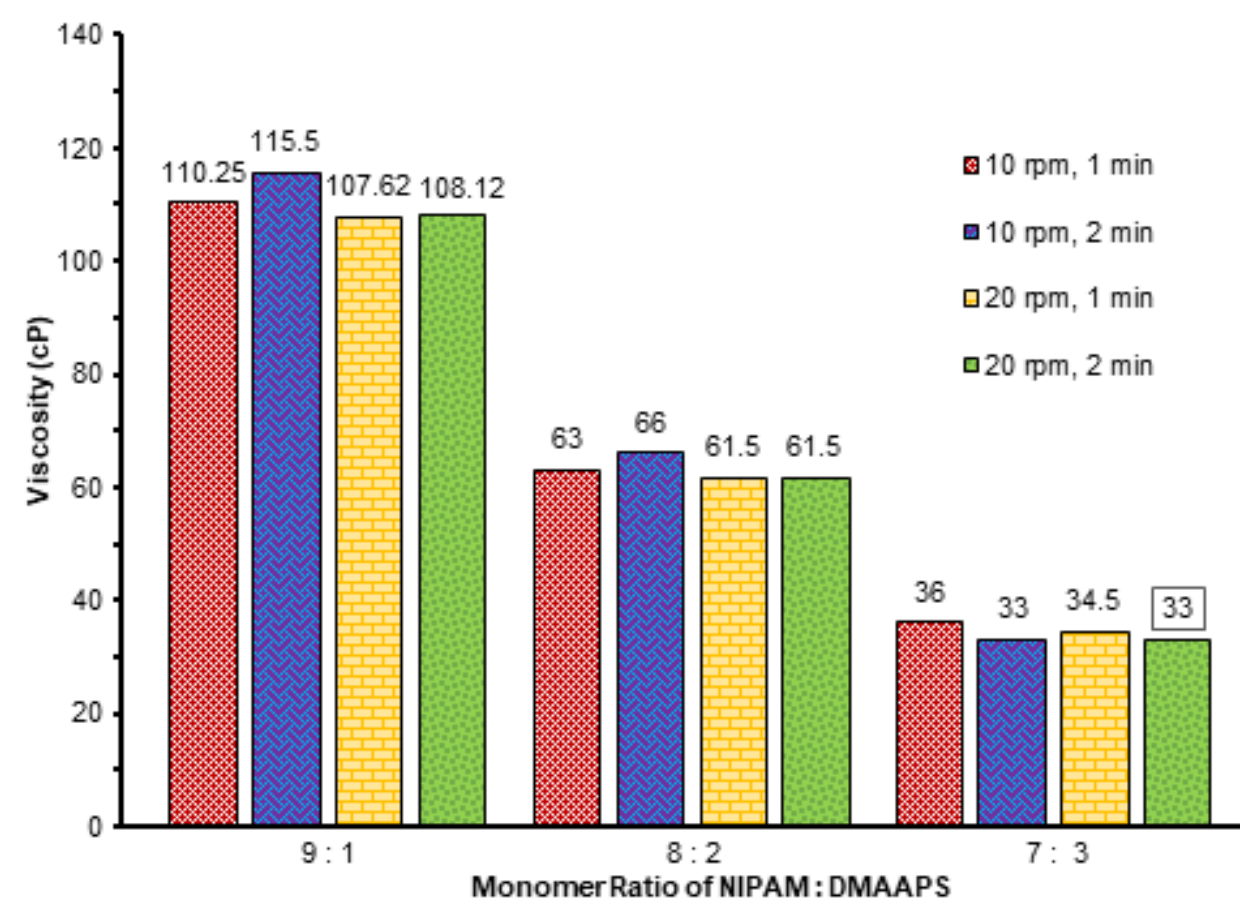

Fig 8. Viscosity of poly(NIPAM-co-DMAAPS) in water of $10 \mathrm{~g} / \mathrm{L}$ at $27^{\circ} \mathrm{C}$ at various monomer ratios

This result confirms that the poly(NIPAM-co-DMAAPS) with higher NIPAM concentration tends to break the intra-chain and intra-group association of charged groups from DMAAPS to form an inter-chain association. The higher the inter-chain association, the more entangled the polymer chain occurs, as a consequence of the increase of hydrophobicity and viscosity copolymer solution.

\section{Transition Temperature}

Fig. 9 shows LCST of poly(NIPAM-co-DMAAPS) solution carried out at $1 \mathrm{~g} / \mathrm{L}$ polymer and a heating rate of $1{ }^{\circ} \mathrm{C} / \mathrm{min}$. The transition temperature is indicated by $50 \%$ of transmittance. The transmittance change as a function of temperature was measured at a wavelength of $600 \mathrm{~nm}$ using a UV/VIS spectrophotometer equipped with a thermostatic cell for polymer solution. The recording of transmittance changes was done during the heating process at a rate of $1{ }^{\circ} \mathrm{C}$. The heating process was applied because transition can be easily observed on heating from a temperature below LCST when the polymer is completely dissolved.

LCST poly(NIPAM-co-DMAAPS) shown in Fig. 9 was strongly affected by monomer concentration and

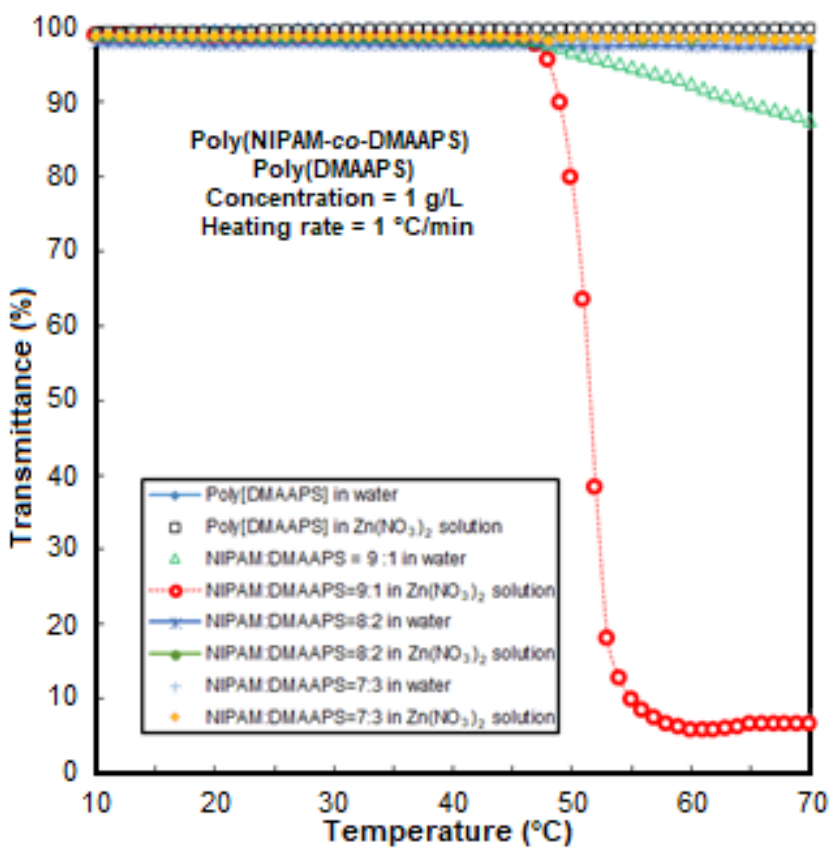

Fig 9. Transition temperature of poly(NIPAM-coDMAAPS) with a polymer concentration of $1 \mathrm{~g} / \mathrm{L}$ at heating rate of $1^{\circ} \mathrm{C} / \mathrm{min}$ and various monomer ratios

solution. Initially, at a lower temperature, polymer with monomer ratio NIPAM:DMAAPS of 9:1 was completely dissolved in water as indicated by the transmittance value reaching almost $100 \%$. Then, the transmittance 
decreases gradually with the increase of temperature from $50-70{ }^{\circ} \mathrm{C}$. However, the transmittance reduction is insignificant, and the transition phase change is not clear. This phenomenon is attributed to the fact that the charge groups interaction, i.e., intra-group, inter-chain, and intra-chain is quite strong, and there is no free ion in water which can bind to the zwitterion in the copolymer chain.

In contrast to a polymer with monomer ratio NIPAM:DMAAPS of 9:1 dissolved in $\mathrm{Zn}\left(\mathrm{NO}_{3}\right)_{2}$ solution, shows a transition temperature at $56.56{ }^{\circ} \mathrm{C}$, this phase transition is in accordance with the initial hypothesis that the copolymer is dominated by NIPAM characteristic of LCST. However, this transition temperature in $\mathrm{Zn}\left(\mathrm{NO}_{3}\right)_{2}$ solution is lower than the transition temperature in water. The polymer solution becomes more hydrophobic in $\mathrm{Zn}\left(\mathrm{NO}_{3}\right)_{2}$ solution because the ions in the solution destroy the hydration layer around the NIPAM molecules in the poly(NIPAM-co-DMAAPS).

This phenomenon is different from poly(DMAAPS) and the copolymer with monomer ratio NIPAM: DMAAPS of 8:2 and 7:3 which does not experience a phase transition both in water and $\mathrm{Zn}\left(\mathrm{NO}_{3}\right)_{2}$ solution.

\section{Correlation between Transition Temperature of the poly(NIPAM-co-DMAAPS) and Adsorption Behavior of the Gels}

The correlation between transition temperature of the poly(NIPAM-co-DMAAPS) with monomer ratio NIPAM:DMAAPS of $9: 1$ and the amount of ions adsorbed onto the gel in $\mathrm{Zn}\left(\mathrm{NO}_{3}\right)_{2}$ solution is shown in Fig. 10. Fig. 10 shows that at a lower temperature of $10-$ $30{ }^{\circ} \mathrm{C}$, the number of ions adsorbed onto NIPAM-coDMAAPS gel in $\mathrm{Zn}\left(\mathrm{NO}_{3}\right)_{2}$ solution was high, and the transmittance of the poly(NIPAM-co-DMAAPS) remained unchanged to nearly $100 \%$. Meanwhile, the percentage of transmittance decreases significantly and clearly shows the transition temperature at $56.56{ }^{\circ} \mathrm{C}$. The number of adsorbed ions begins to decrease at a temperature of $30^{\circ} \mathrm{C}$. Moreover, at higher temperature $50-70{ }^{\circ} \mathrm{C}$ the number of adsorbed ions onto NIPAM-co-DMAAPS gel in $\mathrm{Zn}\left(\mathrm{NO}_{3}\right)_{2}$ solution was the lowest, and the transmittance of the poly(NIPAM-co-DMAAPS) dropped to almost $0 \%$.

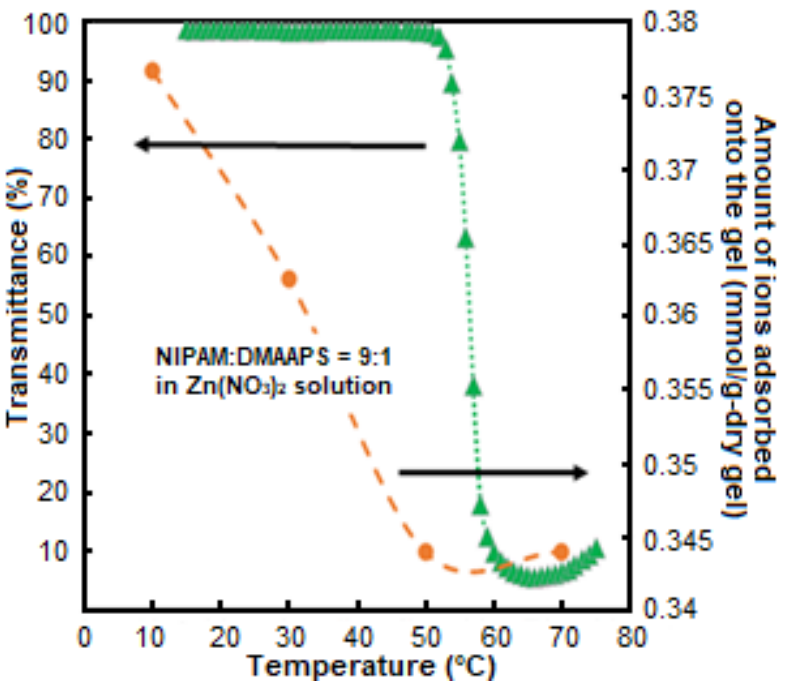

Fig 10. Correlation between transition temperature of the poly(NIPAM-co-DMAAPS) with monomer ratio NIPAM:DMAAPS of 9:1 and the amount of ions adsorbed onto the gel

This phenomenon implies that the higher transmittance is caused by more interaction of ions from solution with the charged groups $\left(\mathrm{N}^{+}\right.$and $\left.\mathrm{SO}_{3^{-}}\right)$of the gel that reduces the chain entanglement and association. In contrast, decreased transmittance shows less number of adsorbed ions because the polymers are more hydrophobic or immiscible in the solution. At that time, the polymer adsorbs a little ion.

\section{- CONCLUSION}

The effect of various monomer ratios of NIPAM:DMAAPS in the preparation of poly(NIPAMco-DMAAPS) on its properties such as transition temperature, molecular structure, and viscosity were systematically investigated in water and $\mathrm{Zn}\left(\mathrm{NO}_{3}\right)_{2}$ solution. The result of FTIR and NMR analysis indicates the success of the copolymerization reaction between NIPAM and DMAAPS in forming the NIPAM-coDMAAPS copolymer. The higher ratio of NIPAM monomer in poly(NIPAM-co-DMAAPS), the lower the LCST of the polymer and the more increase the polymer viscosity. The correlation between transition temperature of the poly(NIPAM-co-DMAAPS) with monomer ratio NIPAM:DMAAPS of 9:1 and the amount of ions adsorbed onto the gel in $\mathrm{Zn}\left(\mathrm{NO}_{3}\right)_{2}$ 
solution was also investigated. As the adsorption amount of ions onto the gel increased, the polymer transmittance increased as well.

\section{- ACKNOWLEDGMENTS}

This research was financially supported by the research grant of Penelitian Pasca Doktor 2018 (959/PKS/ITS/2018) for ten consecutive months from Direktorat Jendral Penguatan Riset dan Pengembangan Kemenristekdikti.

\section{- REFERENCES}

[1] Kusuma, A.H., Prartono, T., Atmadipoera, A.S., and Arifin, T., 2016, Sebaran logam berat terlarut dan terendapkan di perairan teluk Jakarta, Jurnal Teknologi Perikanan dan Kelautan, 6 (1), 41-49.

[2] Cordova, M.R., Purbonegoro, T., Puspitasari, R., and Hindarti, D., 2016, Assessing contamination level of Jakarta bay nearshore sediments using green mussel (Perna viridis) larvae, Mar. Res. Indonesia, 41 (2), 6776.

[3] Plattes, M., Bertrand, A., Schmitt, B., Sinner, J., Verstraeten, F., and Welfring, J., 2007, Removal of tungsten oxyanions from industrial wastewater by precipitation, coagulation and flocculation processes, J. Hazard. Mater., 148 (3), 613-615.

[4] Papadopoulos, A., Fatta, D., Parperis, K., Mentzis, A., Haralambous, K.J., and Loizidou, M., 2004, Nickel uptake from a wastewater stream produced in a metal finishing industry by combination of ionexchange and precipitation methods, Sep. Purif. Technol., 39 (3), 181-188.

[5] Sadrzadeh, M., Mohammadi, T., Ivakpour, J., and Kasiri, N., 2009, Neural network modeling of $\mathrm{Pb}^{2+}$ removal from wastewater using electrodialysis, Chem. Eng. Process., 48 (8), 1371-1381.

[6] Koseoglu, H., and Kitis, M., 2009, The recovery of silver from mining wastewaters using hybrid cyanidation and high-pressure membrane process, Miner. Eng., 22 (5), 440-444.

[7] Fu, F., and Wang, Q., 2011, Removal of heavy metal ions from wastewaters: A review, J. Environ. Manage., 92 (3), 407-418.
[8] Gunatilake, S.K., 2015, Methods of removing heavy metals from industrial wastewater, J. Multidiscip. Eng. Sci. Stud., 1 (1), 12-18.

[9] Álvarez, E.A., Mochón, M.C., Sánchez, J.C.J., and Rodríguez, M.T., 2002, Heavy metal extractable forms in sludge from wastewater treatment plants, Chemosphere, 47 (7), 765-775.

[10] Barakat, M.A., 2011, New trends in removing heavy metals from industrial wastewater, Arabian $\mathrm{J}$. Chem., 4 (4), 361-377.

[11] Liu, J., Ma, Y., Xu, T., and Shao, G., 2010, Preparation of zwitterionic hybrid polymer and its application for the removal of heavy metal ions from water, J. Hazard. Mater., 178 (1-3), 1021-1029.

[12] Neagu, V., Vasiliu, S., and Racovita, S., 2010, Adsorption studies of some inorganic and organic salts on new zwitterionic ion exchangers with carboxybetaine moieties, Chem. Eng. J., 162 (3), 965-973.

[13] Ningrum, E.O., Murakami, Y., Ohfuka, Y., Gotoh, T., and Sakohara, S., 2014, Investigation of ion adsorption properties of sulfobetaine gel and relationship with its swelling behavior, Polymer, 55 (20), 5189-5197.

[14] Takahashi, A., Hamai, K., Okada, Y., and Sakohara, S., 2011, Thermosensitive properties of semi-IPN gel composed of amphiphilic gel and zwitterionic thermosensitive polymer in buffer solutions containing high concentration salt, Polymer, 52 (17), 3791-3799.

[15] Ning, J., Li, G., and Haraguchi, K., 2013, Synthesis of highly stretchable, mechanically tough, zwitterionic sulfobetaine nanocomposite gels with controlled thermosensitivities, Macromolecules, 46 (13), 5317-5328.

[16] Ning, J., Kubota, K., Li, G., and Haraguchi, K., 2013, Characteristics of zwitterionic sulfobetaine acrylamide polymer and the hydrogels prepared by free-radical polymerization and effects of physical and chemical crosslinks on the UCST, React. Funct. Polym., 73 (7), 969-978.

[17] Lee, W.F., and Tsai, C.C., 1994, Synthesis and solubility of the poly (sulfobetaine)s and the 
corresponding cationic polymers: 1 . Synthesis and characterization of sulfobetaines and the corresponding cationic monomers by nuclear magnetic resonance spectra, Polymer, 35 (10), 22102217.

[18] Ningrum, E.O., Ohfuka, Y., Gotoh, T., and Sakohara, S., 2015, Effects of specific anions on the relationship between the ion-adsorption properties of sulfobetaine gel and its swelling behavior, Polymer, 59, 144-154.

[19] Ningrum, E.O., Purwanto, A., Mulyadi, E.O., Dewitasari, D.I., and Sumarno, S., 2017, Adsorption and desorption of $\mathrm{Na}^{+}$and $\mathrm{NO}_{3}^{-}$ions on thermosensitive NIPAM-co-DMAAPS gel in aqueous solution, Indones. J. Chem., 17 (3), 446-452.

[20] Ningrum, E.O., Purwanto, A., Ni'mah, H., Sumarno, Dewitasari, D.I., and Mulyadi, E.O., 2017, Ion adsorption and desorption behaviors of thermosensitive NIPAM-co-DMAAPS gel by temperature swing, AIP Conf. Proc., 1840 (1), 090007.

[21] Ju, C., and Kang, H., 2017, Zwitterionic polymers showing upper critical solution temperature behavior as draw solutes for forward osmosis, RSC $A d v ., 7$ (89), 56426-56432. 